\title{
Ezetimibe ameliorates atherogenic lipids profiles, insulin resistance and hepatocyte growth factor in obese patients with hypercholesterolemia
}

\author{
Hisashi Adachi ${ }^{*}$, Hitoshi Nakano ${ }^{2}$, Kiichiro Yamamoto $^{3}$, Masashi Nakata $^{4}$, Hisatoshi Bekki ${ }^{5}$, Tomoki Honma ${ }^{6}$,
} Hideki Yoshiyama ${ }^{7}$, Masatoshi Nohara ${ }^{8}$ and for the ERASE METS Study Investigators

\begin{abstract}
Background: Ezetimibe ameliorates serum low-density lipoprotein cholesterol (LDL-c) and it has been approved for the treatment of hypercholesterolemia. However, the effects of ezetimibe on specific biomarkers have not been fully clarified in obese Japanese patients.

Methods: A total of 101 patients (47 males and 54 females) were registered in this study during 2011 and 2012. All patients were over 20 years old, were obese [body mass index $(\mathrm{BMI}) \geq 25 \mathrm{~kg} / \mathrm{m}^{2}$ ] and had hypercholesterolemia (LDL-c $\geq 120 \mathrm{mg} / \mathrm{dl}$ ). After excluding 10 subjects (7 who dropped out and 3 with missing data), 91 patients (39 males and 52 females) were analyzed. They were treated with $10 \mathrm{mg}$ ezetimibe once a day for 24 weeks and were evaluated at 12 and 24 weeks.

Results: Following 12 weeks of ezetimibe therapy, BMI ( $p<0.001)$, waist circumference $(p<0.001)$, total cholesterol $(p<0.001)$, LDL-c $(p<0.001)$, non high-density lipoprotein cholesterol $[H D L-c](p<0.001)$, triglycerides $(p<0.05)$ and remnant-like particle cholesterol (RLP-c; $p<0.001)$ were significantly decreased. Following 24 weeks of ezetimibe therapy, BMI $(p<0.05)$, waist circumference $(p<0.001)$, total cholesterol $(p<0.001)$, LDL-c $(p<0.001)$, non HDL-c $(p<0.001)$, triglycerides $(p<0.05)$, RLP-c $(p<0.001)$, insulin $(p<0.05)$ and hepatocyte growth factor $(H G F ; p<0.05)$ were significantly decreased. In contrast, HDL-c $(p<0.001)$ was significantly increased.

Conclusions: Ezetimibe ameliorated not only atherogenic lipid profiles but also anthropometric factors, insulin resistance and biomarkers such as HGF. Ezetimibe may have pleiotropic effects on obese patients with hypercholesterolemia.
\end{abstract}

Keywords: Anti-obesity agents, Metabolic syndrome, Insulin, Hypolipidemic agents

\section{Background}

Ezetimibe is a novel lipid-lowering agent that inhibits intestinal absorption of dietary and biliary cholesterol. The effects of ezetimibe on low-density lipoprotein cholesterol (LDL-c), as well as on baseline lipid profile, hypertension, diabetes mellitus and body mass index (BMI) were found to be generally consistent across all subgroups analyzed [1]. Numerous clinical studies [2-10] have revealed that combination therapy with ezetimibe is beneficial in reducing LDL-c, remnant-like particle cholesterol (RLP-c), and

\footnotetext{
*Correspondence: hadac@med.kurume-u.ac.jp

'Department of Community Medicine, Kurume University School of

Medicine, 67 Asahi-machi, Kurume 830-0011, Japan

Full list of author information is available at the end of the article
}

triglycerides, and in increasing high-density lipoprotein cholesterol (HDL-c) in patients with metabolic syndrome (MetS) or diabetes. Ezetimibe may have more effect in patients with MetS than in non-obese subjects [11]. We and others clarified that the values of RLP-c, aldosterone and hepatocyte growth factor (HGF) were elevated in patients with MetS [12-17]. Moreover, the levels of adiponectine and the ratio of eicosapentaenoic acid to arachidonic acid (EPA/AA) were decreased in patients with MetS [18-20]. The purpose of the present study was to investigate whether the levels of such biomarkers were improved by ezetimibe either in monotherapy or combined therapy in Japanese obese subjects [21].

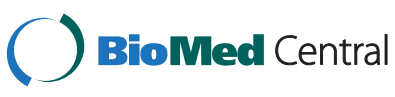

(C) 2015 Adachi et al.; licensee BioMed Central. This is an Open Access article distributed under the terms of the Creative Commons Attribution License (http://creativecommons.org/licenses/by/4.0), which permits unrestricted use, distribution, and reproduction in any medium, provided the original work is properly credited. The Creative Commons Public Domain Dedication waiver (http://creativecommons.org/publicdomain/zero/1.0/) applies to the data made available in this article, unless otherwise stated. 


\section{Results}

Table 1 shows the characteristics of the 101 subjects (47 males and 54 females). The mean age of the subjects was $56.7 \pm 11.3$ years in males and $63.1 \pm 11.6$ years in females. The mean BMI was $27.7 \pm 3.6 \mathrm{~kg} / \mathrm{m}^{2}$ in males and $27.6 \pm$ $3.4 \mathrm{~kg} / \mathrm{m}^{2}$ in females. The mean waist circumference was $94.6 \pm 10.4 \mathrm{~cm}$ in males and $95.7 \pm 8.1 \mathrm{~cm}$ in females. As apparent from Table 1, the prevalence of metabolic syndrome-related factors was high. The mean height $(\mathrm{p}<$ $0.001)$ and weight $(\mathrm{p}<0.001)$ were significantly higher in

Table 1 Characteristics of patients

\begin{tabular}{|c|c|c|c|}
\hline Characteristics & $\begin{array}{l}\text { Males } \\
(n=47)\end{array}$ & $\begin{array}{l}\text { Females } \\
(n=54)\end{array}$ & $p$ \\
\hline Age (years) & $56.7 \pm 11.3$ & $63.1 \pm 11.6$ & 0.0 \\
\hline Height (cm) & $166.9 \pm 5.9$ & $152.9 \pm 8.0$ & $<0.00$ \\
\hline Weight (kg) & $77.3 \pm 12.7$ & $64.6 \pm 10.1$ & $<0.00$ \\
\hline $\begin{array}{l}\text { Body mass } \\
\text { index }\left(\mathrm{kg} / \mathrm{m}^{2}\right)\end{array}$ & $27.7 \pm 3.6$ & $27.6 \pm 3.4$ & 0.9 \\
\hline $\begin{array}{l}\text { Waist circumference } \\
(\mathrm{cm})\end{array}$ & $94.6 \pm 10.4$ & $95.7 \pm 8.1$ & 0.62 \\
\hline $\begin{array}{l}\text { Systolic blood } \\
\text { pressure (mmHg) }\end{array}$ & $129.1 \pm 14.3$ & $127.9 \pm 15.4$ & 0.705 \\
\hline $\begin{array}{l}\text { Diastolic blood } \\
\text { pressure (mmHg) }\end{array}$ & $77.1 \pm 8.5$ & $74.7 \pm 10.4$ & 0.2 \\
\hline $\begin{array}{l}\text { Total cholesterol } \\
(\mathrm{mg} / \mathrm{dl})\end{array}$ & $223.3 \pm 32.6$ & $243.6 .1 \pm 35.1$ & 0.0 \\
\hline $\begin{array}{l}\text { LDL-cholesterol } \\
(\mathrm{mg} / \mathrm{dl})\end{array}$ & $138.7 \pm 26.9$ & $152.2 \pm 29.7$ & 0.020 \\
\hline $\begin{array}{l}\text { HDL-cholesterol } \\
\text { (mg/dl) }\end{array}$ & $48.8 \pm 10.1$ & $53.6 \pm 10.7$ & 0.0 \\
\hline $\begin{array}{l}\text { Non HDL- } \\
\text { cholesterol (mg/dl) }\end{array}$ & $174.5 \pm 29.8$ & $190.1 \pm 31.1$ & 0.01 \\
\hline $\begin{array}{l}\text { Triglycerides* } \\
(\mathrm{mg} / \mathrm{dl})\end{array}$ & $172.4(56-1804)$ & $151.4(62-473)$ & 0.214 \\
\hline $\begin{array}{l}\text { RLP-cholesterol* } \\
(\mathrm{mg} / \mathrm{dl})\end{array}$ & $6.7(2.2-82.5)$ & $6.5(2.4-28.7)$ & 0.868 \\
\hline $\begin{array}{l}\text { Free fatty acid* } \\
(\mathrm{mEq} / \mathrm{l})\end{array}$ & $428.3(92-1423)$ & $437.0(87-1134)$ & 0.8 \\
\hline $\begin{array}{l}\text { Plasma glucose } \\
(\mathrm{mg} / \mathrm{dl})\end{array}$ & $108.5 \pm 26.7$ & $103.4 \pm 29.1$ & 0.360 \\
\hline Insulin* $(\mu \mathrm{U} / \mathrm{ml})$ & $12.9(1.55-200)$ & $10.2(2.82-72.6)$ & 0.180 \\
\hline HOMA index* & $3.36(0.35-80.5)$ & $2.51(0.64-36.2)$ & 0.1 \\
\hline hs CRP* (mg/dl) & 720.5 (50-19100) & 713.4 (50-7910) & 0.990 \\
\hline $\begin{array}{l}\text { Aldosterone } \\
(\mathrm{pg} / \mathrm{dl})^{*}\end{array}$ & $95.6(42.2-315.0)$ & 85.6 (37.9-296.0) & 0.238 \\
\hline HGF (ng/ml) & $0.32 \pm 0.05$ & $0.31 \pm 0.06$ & 0.731 \\
\hline $\begin{array}{l}\text { Adiponectine } \\
(\mu \mathrm{g} / \mathrm{ml})^{*}\end{array}$ & $1.97(0.28-10.6)$ & $3.21(0.30-8.34)$ & 0.001 \\
\hline EPA/AA* & $0.35(0.10-2.05)$ & $0.30(0.10-1.59)$ & 0.22 \\
\hline
\end{tabular}

Data are means (SD), geometric mean and range. *: These variables are shown in the original scale after analysis using log (natural)-transformed values.

Abbreviations: RLP Remnant-like particle cholesterol, HOMA Homeostasis model assessment, HGF Hepatocyte growth factor, EPA/AA Eicosapentaenoic acid to arachidonic acid.

males than in females. The mean age $(\mathrm{p}<0.01)$, total cholesterol $(\mathrm{p}<0.01)$, LDL-c $(\mathrm{p}<0.05)$, HDL-c $(\mathrm{p}<0.05)$, non HDL-c $(\mathrm{p}<0.05)$ and adiponectine $(\mathrm{p}<0.01)$ were significantly lower in males than in females.

Table 2 shows the anthropometric and laboratory data before, at 12 weeks, and at 24 weeks after ezetimibe treatments. Following 12 weeks of ezetimibe therapy, BMI ( $\mathrm{p}<$ $0.001)$, waist circumference $(\mathrm{p}<0.001)$, total cholesterol $(\mathrm{p}<0.001)$, LDL-c $(\mathrm{p}<0.001)$, non HDL-c $(\mathrm{p}<0.001)$, triglycerides $(\mathrm{p}<0.05)$ and RLP-c $(\mathrm{p}<0.001)$ were significantly decreased. Following 24 weeks of ezetimibe therapy, BMI $(\mathrm{p}<0.05)$, waist circumference $(\mathrm{p}<0.001)$, total cholesterol ( $\mathrm{p}<0.001)$, LDL-c $(\mathrm{p}<0.001)$, non HDL-c $(\mathrm{p}<0.001)$, triglycerides $(\mathrm{p}<0.05)$, RLP-c $(\mathrm{p}<0.001)$, insulin $(\mathrm{p}<0.05)$ and HGF $(\mathrm{p}<0.05)$ were significantly decreased. In contrast, HDL-c $(\mathrm{p}<0.001)$ was significantly increased. There were no significant changes in systolic

Table 2 Lipids and other biomarkers at baseline and at 3 and 6 months after the ezetimibe therapy

\begin{tabular}{lccc}
\hline Parameters & Pre & Post 3M & Post 6M \\
\hline $\begin{array}{l}\text { Body mass index } \\
\left(\mathrm{kg} / \mathrm{m}^{2}\right)\end{array}$ & $27.9 \pm 3.5$ & $27.5 \pm 3.4^{* * *}$ & $27.6 \pm 3.4^{*}$ \\
$\begin{array}{l}\text { Waist circumference } \\
(\mathrm{cm})\end{array}$ & $93.6 \pm 8.5$ & $91.8 \pm 7.8^{* * *}$ & $91.5 \pm 7.9^{* * *}$ \\
$\begin{array}{l}\text { Systolic blood } \\
\text { pressure (mmHg) }\end{array}$ & $128.7 \pm 14.8$ & $127.2 \pm 13.9$ & $127.0 \pm 13.0$ \\
$\begin{array}{l}\text { Diastolic blood } \\
\text { pressure (mmHg) }\end{array}$ & $76.0 \pm 9.4$ & $75.6 \pm 9.4$ & $74.4 \pm 10.3$ \\
$\begin{array}{l}\text { Total cholesterol } \\
(\mathrm{mg} / \mathrm{dl})\end{array}$ & $236.2 \pm 34.7$ & $208.9 \pm 31.9^{* * *}$ & $207.0 \pm 34.5^{* * *}$ \\
$\begin{array}{l}\text { LDL-cholesterol } \\
(\mathrm{mg} / \mathrm{dl})\end{array}$ & $147.9 \pm 29.5$ & $125.5 \pm 25.9^{* * *}$ & $126.5 \pm 30.5^{* * *}$ \\
& & &
\end{tabular}
$(\mathrm{mg} / \mathrm{dl})$

$\mathrm{HDL}$-cholesterol $(\mathrm{mg} / \mathrm{dl})$

Non HDL-cholestero $(\mathrm{mg} / \mathrm{dl})$

Triglycerides $^{+}(\mathrm{mg} / \mathrm{dl})$

$51.7 \pm 10.7 \quad 52.7 \pm 10.3 \quad 54.5 \pm 9.8^{* * *}$

$184.5 \pm 30.7 \quad 156.2 \pm 29.1^{* * *} 151.9 \pm 32.6^{* * *}$ RLP-cholesterol ${ }^{+}(\mathrm{mg} / \mathrm{dl})$

6.6

Free fatty $\operatorname{acid}^{+}(\mathrm{mEq} / \mathrm{l})$

Plasma glucose $(\mathrm{mg} / \mathrm{dl})$

Insulin ${ }^{+}(\mu \mathrm{U} / \mathrm{ml})$

HOMA index ${ }^{+}$

$\mathrm{hsCRP}^{+}(\mathrm{mg} / \mathrm{dl})$

Aldosterone $(\mathrm{pg} / \mathrm{dl})^{+}$

HGF (ng/ml)

Adiponectine $(\mu \mathrm{g} / \mathrm{ml})^{+}$

$\mathrm{EPA} \mathrm{AA}^{+}$

$*: p<0.05, * *: p<0.001$

Data are means (SD), geometric mean and range. *: These variables are shown in the original scale after analysis using log (natural)-transformed values.

Abbreviations: RLP Remnant-like particle cholesterol, HOMA Homeostasis model assessment, HGF Hepatocyte growth factor, EPA/AA Eicosapentaenoic acid to arachidonic acid. 
and diastolic blood pressure (BP), free fatty acid (FFA), plasma glucose, homeostasis model assessment (HOMA) index, high sensitive CRP (hsCRP), aldosterone, adiponectine or EPA/AA.

Table 3 shows the anthropometric and laboratory data before and at 24 weeks after ezetimibe monotherapy or combined therapy. Following 24 weeks of ezetimibe monotherapy, BMI $(\mathrm{p}<0.05)$, waist circumference $(\mathrm{p}<$ $0.001)$, systolic $(\mathrm{p}<0.05)$ and diastolic $(\mathrm{p}<0.05)$ BP, total cholesterol ( $\mathrm{p}<0.001)$, LDL-c $(\mathrm{p}<0.001)$, non HDL-c $(\mathrm{p}<$ $0.001)$, triglycerides $(\mathrm{p}<0.05)$, RLP-c $(\mathrm{p}<0.01)$, plasma glucose $(\mathrm{p}<0.05)$, insulin $(\mathrm{p}<0.01)$, HOMA index $(\mathrm{p}<$ $0.01)$ and HGF $(\mathrm{p}<0.05)$ were significantly decreased. In contrast, HDL-c $(\mathrm{p}<0.001)$ was significantly increased. Following 24 weeks of combined therapy, BMI $(\mathrm{p}<0.05)$, waist circumference $(\mathrm{p}<0.01)$, total cholesterol $(\mathrm{p}<0.05)$, LDL-c $(\mathrm{p}<0.05)$, non HDL-c $(\mathrm{p}<0.01)$, triglycerides $(\mathrm{p}<$ $0.001)$ and RLP-c $(\mathrm{p}<0.001)$ were significantly decreased. In contrast, HDL-c $(\mathrm{p}<0.001)$ was significantly increased.

\section{Discussion}

Twenty-four weeks of ezetimibe treatment ameliorated not only atherogenic lipid profiles but also anthropometric factors, insulin resistance and biomarkers such as HGF. To the best of our knowledge, this is the first report to show that ezetimibe treatment reduced HGF levels in obese patients with hypercholesterolemia.

Although many studies [3-10] have reported that ezetimibe treatment ameliorated atherogenic lipid profiles, very few $[22,23]$ have referred to anthropometric data. One report from Japan [22] found no significant differences in body weight and BMI after ezetimibe treatment. Other Japanese investigators [24] also suggested that there were no significant changes in metabolic markers including BMI and waist circumference before and after ezetimibe treatment. Although Yagi S, et al. [23] demonstrated that ezetimibe treatment significantly reduced body weight, BMI, waist circumference and BP, they did not discuss the reason. Our data were consistent with theirs in large part.

Table 3 Laboratory findings before and after ezetimibe monotherapy and combined therapy

\begin{tabular}{|c|c|c|c|c|}
\hline & Monotherapy & $(n=71)$ & $\begin{array}{c}\text { Combined } \\
\text { therapy }\end{array}$ & $(n=20)$ \\
\hline Parameters & Pre & Post 6M & Pre & Post 6M \\
\hline $\begin{array}{l}\text { Body mass } \\
\text { index }\left(\mathrm{kg} / \mathrm{m}^{2}\right)\end{array}$ & $28.2 \pm 3.7$ & $28.0 \pm 3.8$ & $27.2 \pm 2.0$ & $25.9 \pm 1.6^{*}$ \\
\hline $\begin{array}{l}\text { Waist } \\
\text { circumference }(\mathrm{cm})\end{array}$ & $94.6 \pm 8.2$ & $92.8 \pm 8.6^{* * *}$ & $91.0 \pm 5.6$ & $88.3 \pm 5.3^{* *}$ \\
\hline $\begin{array}{l}\text { Systolic blood } \\
\text { pressure (mmHg) }\end{array}$ & $130.1 \pm 14.6$ & $128.8 \pm 13.2^{*}$ & $125.6 \pm 13.8$ & $121.8 \pm 11.2$ \\
\hline $\begin{array}{l}\text { Diastolic blood } \\
\text { pressure (mmHg) }\end{array}$ & $77.3 \pm 9.5$ & $75.9 \pm 10.6^{*}$ & $71.7 \pm 8.2$ & $69.5 \pm 7.7$ \\
\hline Total cholesterol (mg/dl) & $237.9 \pm 35.9$ & $212.0 \pm 33.0^{* * *}$ & $224.7 \pm 27.8$ & $192.2 \pm 36.1^{*}$ \\
\hline LDL-cholesterol (mg/dl) & $151.3 \pm 28.6$ & $132.4 \pm 28.6^{* * *}$ & $132.1 \pm 26.8$ & $107.8 \pm 30.5^{*}$ \\
\hline HDL-cholesterol (mg/dl) & $51.9 \pm 9.9$ & $55.1 \pm 9.4^{* * *}$ & $50.8 \pm 11.9$ & $53.3 \pm 11.5^{* * *}$ \\
\hline Non HDL-cholesterol (mg/dl) & $184.9 \pm 31.7$ & $155.6 \pm 32.5^{* * *}$ & $174.6 \pm 25.8$ & $141.8 \pm 32.2^{* *}$ \\
\hline Triglycerides $^{+}$(mg/dl) & 157.5 & $129.2^{* * *}$ & 210.9 & $155.3^{* * *}$ \\
\hline RLP-cholesterol $^{+}$(mg/dl) & 6.3 & $4.7^{* *}$ & 8.2 & $4.7^{* * *}$ \\
\hline Free fatty acid ${ }^{+}(\mathrm{mEq} / \mathrm{l})$ & 435.9 & $505.6^{*}$ & 435.4 & 429.7 \\
\hline Plasma glucose (mg/dl) & $105.1 \pm 27.9$ & $102.6 \pm 26.4^{*}$ & $109.3 \pm 21.7$ & $105.1 \pm 15.9$ \\
\hline Insulin ${ }^{+}(\mu \mathrm{U} / \mathrm{ml})$ & 12.1 & $9.6^{* *}$ & 11.7 & 11.4 \\
\hline HOMA index ${ }^{+}$ & 3.0 & $2.4^{* *}$ & 3.2 & 2.9 \\
\hline $\mathrm{hsCRP}^{+}(\mathrm{mg} / \mathrm{dl})$ & 807.0 & $883.7^{*}$ & 686.1 & $879.6^{*}$ \\
\hline Aldosterone $(\mathrm{pg} / \mathrm{dl})^{+}$ & 86.9 & $92.9^{*}$ & 101.6 & 110.8 \\
\hline HGF (ng/ml) & $0.33 \pm 0.07$ & $0.31 \pm 0.04^{*}$ & $0.31 \pm 0.03$ & $0.30 \pm 0.02$ \\
\hline Adiponectine $(\mu \mathrm{g} / \mathrm{ml})^{+}$ & 2.51 & 2.56 & 2.49 & 2.47 \\
\hline $\mathrm{EPA} \mathrm{AA}^{+}$ & 0.29 & 0.28 & 0.39 & 0.40 \\
\hline
\end{tabular}

${ }^{*}: p<0.05,{ }^{* *}: p<0.01,{ }^{* * *}: p<0.001$.

Data are means (SD), geometric mean and range. *: These variables are shown in the original scale after analysis using log (natural)-transformed values. Abbreviations: RLP Remnant-like particle cholesterol, HOMA Homeostasis model assessment, HGF Hepatocyte growth factor, EPA/AA Eicosapentaenoic acid to arachidonic acid. 
One possible explanation is that ezetimibe markedly reduced visceral fat as assessed by abdominal computed tomography [25]. Our data and others [23-25] suggested that ezetimibe may play a unique role in the treatment of metabolic syndrome. The present study revealed that ezetimibe treatment also ameliorated insulin resistance in addition to lipid profiles. In one experimental study, ezetimibe was shown to improve insulin resistance in Zucker fatty rats, a model of obesity [26].

We confirmed that ezetimibe improves HOMA index as a marker of insulin resistance. Dagli N, et al. [27] reported that low-dose statin (pravastatin) and ezetimibe combination therapy improved insulin resistance markedly better than high-dose pravastatin monotherapy. This suggested that combined antilipidemic therapy may be a more favorable treatment alternative in high-risk dyslipidemic patients. Hiramitsu S, et al. [24] also demonstrated that ezetimibe significantly reduced the fasting insulin level ( $-12.8 \%$ reduction) and glycosylated hemoglobin $\mathrm{A}_{1 \mathrm{c}}\left[\mathrm{HbA}_{1 \mathrm{c}}\right]$ (-3.4\% reduction). However, Kikuchi $\mathrm{K}$, et al. [28] reported that ezetimibe restored the postprandial dysregulation of lipid but did not affect glucose metabolism in a double-blind randomized crossover trial.

Interestingly, ezetimibe monotherapy was more effective than combined therapy in reducing insulin and HOMA index in this study. These results may be consistent with our recent report [29].

We have shown that HGF levels as well as RLP-c were significantly reduced by twenty-four weeks of ezetimibe treatment. Our colleagues [16] demonstrated that HGF levels were significantly and strongly associated with metabolic syndrome. HGF is one of the adipocytokines. A report [30] described the relationship between obesity and serum HGF levels. It may be feasible to consider that the elevated HGF levels in obese subjects may be due to fatty liver secondary to obesity. It is interesting to note that results of the present study using ezetimibe only $(n=83)$ are consistent with a previous report [13]. Taken together, candidate subjects suitable for ezetimibe monotherapy may have multiple syndromes with underlying insulin resistance.

A limitation of our study is that it was an observational study without a control group. This study design did not allow us to evaluate the impact of ezetimibe on insulin resistance over time. In this study population, we also recommended standard diet and exercise therapies. To exclude the effects of the standard diet and exercise therapies, we examined additional data from another cohort. We enrolled 60 subjects, who received health check-up examinations in 2001 and 2003 in Uku town in Japan, who took no medicine, and who were recommended standard diet and exercise therapies. Their HOMA-IR was $1.21 \pm 0.84$ at baseline in 2001 and $1.31 \pm$ 0.87 at 2 -year follow-up in 2003. This group showed no significant change in insulin resistance $(p=0.272)$, suggesting that standard diet and exercise therapies have no significant effects on insulin resistance. Second, this study was conducted in Japan, where the incidence of obesity is low compared with Caucasians. A final limitation is that the number of participants and the follow-up period may have been insufficient to fully elucidate the role of ezetimibe. Nevertheless, the pleiotropic effects of the ezetimibe treatment were striking and deserve further investigation. Additional studies of ezetimibe with a large sample size including predictive measures of major atherosclerotic diseases are needed.

\section{Conclusions}

In conclusion, ezetimibe ameliorated not only atherogenic lipid profiles but also anthropometric factors, insulin resistance and biomarkers such as HGF. Ezetimibe may have pleiotropic effects on obese patients with hypercholesterolemia.

\section{Methods}

\section{Ethical statement}

This study was approved by the Institutional Review Board of Community Medicine, Kurume University School of Medicine, as well as by the ethics committee of Kurume University. All subjects participated in the study after making signed informed consents.

\section{Study population and data collection}

All outpatients aged over 20 years with obesity (BMI $\geq$ $25 \mathrm{~kg} / \mathrm{m}^{2}$ ) and hypercholesterolemia (LDL-c $\geq 120 \mathrm{mg} / \mathrm{dl}$ ) were registered in this study at Kurume University Hospital or nearby clinics during 2011 and 2012. After excluding 10 subjects (7 who dropped out and 3 with missing data), 91 patients (39 males and 52 females) were analyzed.

The study was named ERASE METS (Effects on Regression of $A$ theroSclerotic risks by Ezetimibe for the patients with METabolic Syndrome) by one of the study investigators (T.H.). The enrolled subjects were treated with $10 \mathrm{mg}$ ezetimibe once a day for 24 weeks and were evaluated at 12 and 24 weeks. We divided the patients into two groups, one without anti-dyslipidemic agents (ezetimibe monotherapy, $\mathrm{n}=71$ ) and the other with a statin (combined therapy, $\mathrm{n}=20$ ). Standard diet and exercise therapy for dyslipidemia were recommended during the study. Height was measured with shoes on and weight was measured with the patients in their ordinary clothing. BMI was calculated as weight (kilograms) divided by the square of height (square meters) as an index of obesity. In Japan, obesity is defined as BMI over $25 \mathrm{~kg} / \mathrm{m}^{2}$. Waist circumference was measured at the level of the umbilicus in the standing position. BP was measured in the supine position twice at 3-min intervals using an upright standard sphygmomanometer. Vigorous physical activity and smoking were avoided for at 
least 30 min before BP measurement. The second BP with the fifth-phase diastolic pressure was used for analysis. Blood was drawn from the antecubital vein in the morning after a 12-hour fast for determinations of lipids profiles [total cholesterol, LDL-c, triglycerides, HDL-c, non-HDL-c and RLP-c], free fatty acid (FFA), fasting plasma glucose (FPG), fasting immune-reactive insulin (IRI), high-sensitivity C-reactive protein (hs-CRP), aldosterone, HGF, adiponectine and EPA/AA. Fasting blood samples were centrifuged within 1 hour after collection. The serum levels of total cholesterol, LDL-c, triglycerides, HDL-c and non-HDL-c, FFA, FPG and IRI were measured using standard laboratory methods. Serum RLP-c was measured by immune-separation technique [31] (using an immune-affinity gel containing monoclonal antibodies to human apolipoprotein [apo] B-100 and apo A-1). HOMA index was calculated as FPG $(\mathrm{mg} / \mathrm{dL}) \times$ fasting IRI $(\mu \mathrm{U} /$ $\mathrm{mL}) / 405$ and used as a marker of insulin resistance [32]. Hs-CRP was measured as an inflammatory marker. Plasma aldosterone was measured in the morning by radioimmunoassay (RIA), and samples were taken after the subjects had remained in a sitting position for 10 minutes [14]. Plasma HGF levels were measured by the enzyme-linked immunosorbent assay (ELISA) [33]. Serum adiponectin concentrations were measured by radioimmunoassay [18]. Measurement of serum EPA/AA levels were outsourced to SRL (Fukuoka, Japan) [20]. All of the blood tests except for HGF, adiponectin and EPA/AA were measured in a commercially available laboratory (The Kyodo Igaku Laboratory, Fukuoka, Japan).

\section{Statistical analysis}

Results are presented as the mean \pm standard deviation. Variables that were not normally distributed and/or displayed homogeneity of variances were analyzed by Mann-Whitney test for independent samples. Normally distributed variables were analyzed using a paired $t$ test. The $\mathrm{p}$-values $<0.05$ were considered statistically significant. All statistical analyses were performed using SAS version 9.3 (SAS Inc., Cary, NC, USA).

\section{Abbreviations \\ LDL-c: Low-density lipoprotein cholesterol; BMI: Body mass index; HDL: High- density lipoprotein; RLP-c: Remnant-like particle cholesterol; HGF: Hepatocyte growth factor; MetS: Metabolic syndrome; EPA: Eicosapentaenoic acid; AA: Arachidonic acid; BP: Blood pressure; HOMA: Homeostasis model assessment; $\mathrm{HbA}_{1}$ : Glycosylated hemoglobin $\mathrm{A}_{1}$; FFA: Free fatty acid; FPG: Fasting plasma glucose; IRI: Immune-reactive insulin; Hs-CRP: High- sensitivity C-reactive protein; RIA: Radioimmunoassay; ELISA: Enzyme-linked immunosorbent assay.}

\section{Competing interests}

The authors declare that they have no competing interests.

\section{Author' contributions}

HA performed this study and statistical analyses, and TH named the study ERASE METS. HN, KY, MNa, HB, TH, HY and MNo designed this study. All authors read and approved the final manuscript.

\section{Acknowledgements}

We are grateful to the members of the Japan Medical Association of Ukiha, the elected officials and residents of Tanushimaru, and the team of cooperating physicians for their help in performing the health examinations. This study was supported in part by the Kimura Memorial Heart Foundation (Fukuoka, Japan) and by Bayer Pharmaceutical Co., Ltd.

\section{Author details}

${ }^{1}$ Department of Community Medicine, Kurume University School of Medicine, 67 Asahi-machi, Kurume 830-0011, Japan. ${ }^{2}$ Nakano Medical Clinic, Chikugo, Japan. ${ }^{3}$ Yamamoto Clinic, Chikugo, Japan. ${ }^{4}$ Nakata Clinic, Kurume, Japan. ${ }^{5}$ Bekki Clinic, Yame, Japan. ${ }^{6}$ Honma Clinic, Kurume, Japan. ${ }^{7}$ Yoshiyama Medical Clinic, Chikugo, Japan. ${ }^{8}$ Nohara Clinic, Kurume, Japan.

Received: 15 August 2014 Accepted: 27 December 2014 Published: 10 January 2015

\section{References}

1. Knopp RH, Dujovne CA, Le Beaut A, Lipka LJ, Suresh R, Veltri EP, et al. Evaluation of efficacy, safety, and tolerability of ezetimibe in primary hypercholesterolaemia: a pooled analysis from two controlled phase III clinical studies. Int J Clin Pract. 2003:57:363-8.

2. Denke M, Pearson T, Mcbride P, Gazzara RA, Brady WE, Tershakovec AM. Ezetimibe added to ongoing statin therapy improves LDL-C goal attainment and lipid profile in patients with diabetes or metabolic syndrome. Diabetes Vasc Dis Res. 2006;3:93-102.

3. Hajer GR, Dallinga-Thie GM, van Vark-van der Zee LC, Visseren FL. The effect of statin alone or in combination with ezetimibe on postprandial lipoprotein composition in obese metabolic syndrome patients. Atherosclerosis. 2009:202:216-24.

4. Winkler K, Schewe T, Pütz G, Ödünc N, Schäfer G, Siegel E, et al. Fluvastatin/ fenofibrate vs. simvastatin/ ezetimibe in patients with metabolic syndrome: different effects on LDL-profiles. Eur J Clin Invest. 2009;39:463-70.

5. Robinson JG, Ballantyne CM, Grundy SM, Hsueh WA, Parving HH, Rosen JB, et al. Lipid-altering efficacy and safety of ezetimibe/ simvastatin versus atorvastatin in patients with hypercholesterolemia and the metabolic syndrome (from the WYMET Study). Am J Cardiol. 2009;103:1694-702.

6. Goldberg RB, Guyton JR, Mazzone T, Weinstock RS, Polis AB, Tipping D, et al. Relationships between metabolic syndrome and other baseline factors and the efficacy of ezetimibe/ simvastatin and atorvastatin in patients with type 2 diabetes and hypercholesterolemia. Diabetes Care. 2010;33:1021-4.

7. Conard S, Bays H, Leiter LA, Bird S, Lin J, Hanson ME, et al. Ezetimibe added to atorvastatin compared with doubling the atorvastatin dose in patients at high risk for coronary heart disease with diabetes mellitus, metabolic syndrome or neither. Diabetes Obes Metab. 2010;12:210-8.

8. Miller M, DiNicolantonio JJ, Can M, Grice R, Damoulakis A, Serebruany VL. The effects of ezetimibe/simvastatin versus simvastatin monotherapy on platelet and inflammatory biomarkers in patients with metabolic syndrome. Cardiology. 2013;125:74-7.

9. Rosen JB, Jimenez JG, Pirags V, Vides $H$, Hanson ME, Massaad R, et al. A comparison of efficacy and safety of an ezetimibe/simvastatin combination compared with other intensified lipid-lowering treatment strategies in diabetic patients with symptomatic cardiovascular disease. Diab Vasc Dis Res. 2013;10:277-86.

10. Bays HE, Shah A, Macdonell G, Taggart WV, Gumbiner B. Effects of coadministered ezetimibe plus fenofibrate in mixed dyslipidemic patients with metabolic syndrome. Metab Syndr Relat Disord. 2011;9:135-42.

11. Averna M, Missault L, Vaverkova $H$, Farnier M, Viigimaa $M$, Dong $Q$, et al. Lipid-altering efficacy of switching to ezetimibe/simvastatin 10/20 mg versus rosuvastatin $10 \mathrm{mg}$ in high-risk patients with and without metabolic syndrome. Diab Vasc Dis Res. 2011;8:262-70.

12. Satoh A, Adachi H, Tsuruta M, Hirai Y, Hiratsuka A, Enomoto M, et al. High plasma level of remnant-like particle cholesterol in the metabolic syndrome. Diabetes Care. 2005:28:2514-8.

13. Kotani K, Asahara-Satoh N, Kato Y, Araki R, Himeno A, Yamakage H, et al. Remnant-like particle cholesterol and serum amyloid A-low-density lipoprotein levels in obese subjects with metabolic syndrome. J Clin Lipidol. 2011:5:395-400.

14. Kumagai E, Adachi H, Jacobs Jr DR, Hirai Y, Enomoto M, Fukami A, et al. Plasma aldosterone levels and development of insulin resistance: prospective study in a general population. Hypertension. 2011;58:1043-8. 
15. Musani SK, Vasan RS, Bidulescu A, Liu J, Xanthakis V, Sims M, et al, Aldosterone, C-reactive protein, and plasma B-type natriuretic peptide are associated with the development of metabolic syndrome and longitudinal changes in metabolic syndrome components: findings from the Jackson Heart Study. Diabetes Care. 2013;36:3084-92.

16. Hiratsuka A, Adachi H, Fujiura Y, Yamagishi S, Hirai Y, Enomoto M, et al. Strong association between serum hepatocyte growth factor and metabolic syndrome. J Clin Endocrinol Metab. 2005;90:2927-31.

17. Balaban YH, Sumer H, Simsek H, Us D, Tatar G. Metabolic syndrome, nonalcoholic steatohepatitis (NASH), and hepatocyte growth factor (HGF). Ann Hepatol. 2006;5:109-14.

18. Kim JY, Ahn SV, Yoon JH, Koh SB, Yoon J, Yoo BS, et al. Prospective study of serum adiponectin and incident metabolic syndrome: the ARIRANG study. Diabetes Care. 2013;36:1547-53.

19. Kawamoto R, Tabara Y, Kohara K, Miki T, Kusunoki T, Takayama S, et al. Relationships between lipid profiles and metabolic syndrome, insulin resistance and serum high molecular adiponectin in Japanese communitydwelling adults. Lipids Health Dis. 2011;10:79.

20. Inoue K, Kishida K, Hirata A, Funahashi T, Shimomura I. Low serum eicosapentaenoic acid/arachidonic acid ratio in male subjects with visceral obesity. Nutr Metab (Lond). 2013;10:25.

21. Tiwari $\mathrm{V}$, Khokhar M. Mechanism of action of anti- hypercholesterolemia drugs and their resistance. Eur J Pharmacol. 2014;741:156-70.

22. Tamaki N, Ueno H, Morinaga Y, Shiiya T, Nakazato M. Ezetimibe ameliorates atherosclerotic and inflammatory markers, atherogenic lipid profiles, insulin sensitivity, and liver dysfunction in Japanese patients with hypercholesterolemia. J Atheroscler Thromb. 2012;19:532-8.

23. Yagi S, Akaike M, Aihara KI, Iwase T, Ishikawa K, Yoshida S, et al. Ezetimibe ameliorates metabolic disorders and microalbuminuria in patients with hypercholesterolemia. J Atheroscler Thromb. 2010;17:173-80.

24. Hiramitsu S, Ishiguro Y, Matsuyama H, Yamada K, Kato K, Noba M, et al. The effects of ezetimibe on surrogate markers of cholesterol absorption and synthesis in Japanese patients with dyslipidemia. J Atheroscler Thromb. 2010;17:106-14.

25. Takase H, Dohi Y, Okado T, Hashimoto T, Goto Y, Kimura G. Effects of ezetimibe on visceral fat in the metabolic syndrome: a randomized controlled study. Eur J Clin Invest. 2012;42:1287-94.

26. Deushi M, Nomura M, Kawakami A, Haraguchi M, Ito M, Okazaki M, et al. Ezetimibe improves liver steatosis and insulin resistance in obese rat model of metabolic syndrome. FEBS Lett. 2007:581:5664-70.

27. Dagli N, Yavuzkir M, Karaca I. The effects of high dose pravastatin and low dose pravastatin and ezetimibe combination therapy on lipid, glucose metabolism and inflammation. Inflammation. 2007:30:230-5

28. Kikuchi K, Nezu U, Inazumi K, Miyazaki T, Ono K, Orime K, et al. Double-blind randomized clinical trial of the effects of ezetimibe on postprandial hyperlipidemia and hyperglycaemia. J Atheroscler Thromb. 2012;19:1093-101.

29. Ohbu-Murayama K, Adachi H, Hirai Y, Enomoto M, Fukami A, Obuchi A, et al. Ezetimibe combined with standard diet and exercise therapy improves insulin resistance and atherosclerotic markers in patients with metabolic syndrome. J Diab Invest. 2014. in press.

30. Rehman J, Considene RV, Bovenkerk JE, Li J, Slavens CA, Jones R, et al. Obesity is associated with increased levels of circulating hepatocyte growth factor. J Am Coll Cardiol. 2003:41:1408-13.

31. Nakajima K, Okazaki M, Tanaka A, Pullinger CR, Wang T, Nakano T, et al. Separation and determination of remnant-like particles in human serum using monoclonal antibodies to apo B-100 and apo A-I. J Clin Ligand Assay. 1996;19:177-83.

32. Matthews DR, Hosker JP, Rudenski AS, Naylor BA, Treacher DF, Turner RC Homeostasis model assessment: insulin resistance and beta-cell function from fasting plasma glucose and insulin concentrations in man. Diabetologia. 1985;28:412-9.

33. Yamada A, Matsumoto K, Iwanari H, Sekiguchi K, Kawata S, Matsuzawa Y, et al. Rapid and sensitive enzyme-linked immunosorbent assay for measurement of HGF in rat and human tissues. Biomed Res. 1995;16:105-14.

doi:10.1186/1476-511X-14-1

Cite this article as: Adachi et al.: Ezetimibe ameliorates atherogenic lipids profiles, insulin resistance and hepatocyte growth factor in obese patients with hypercholesterolemia. Lipids in Health and Disease 2015 14:1.

\section{Submit your next manuscript to BioMed Central and take full advantage of:}

- Convenient online submission

- Thorough peer review

- No space constraints or color figure charges

- Immediate publication on acceptance

- Inclusion in PubMed, CAS, Scopus and Google Scholar

- Research which is freely available for redistribution 